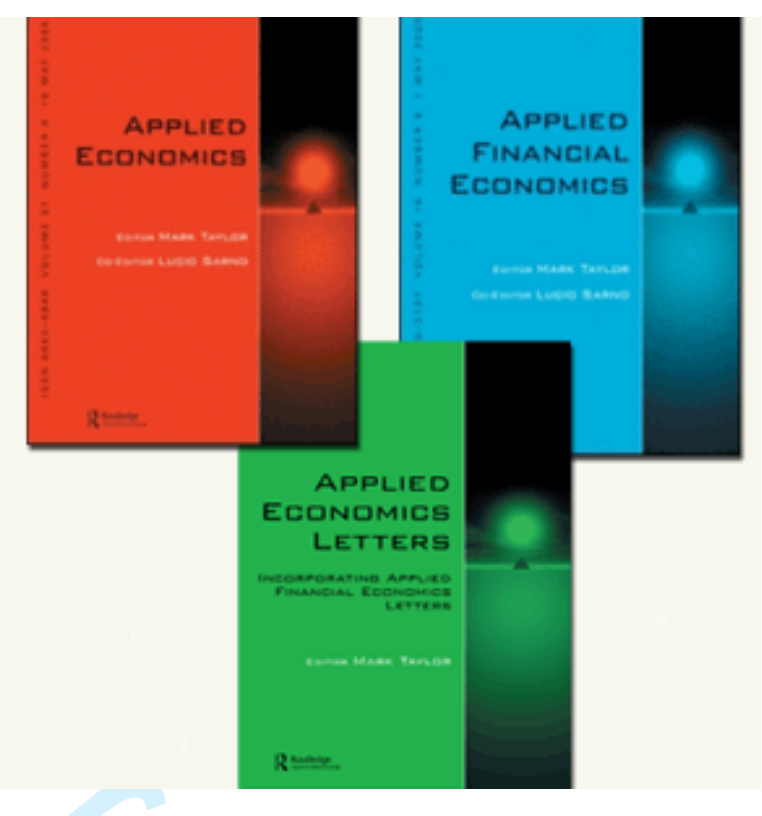

\title{
Predicting entrepreneurial behaviour: a test of the theory of planned behaviour
}

\begin{tabular}{|r|l|}
\hline Journal: & Applied Economics \\
\hline Manuscript ID: & APE-2010-0110.R1 \\
\hline Journal Selection: & Applied Economics \\
\hline Date Submitted by the & 11-Mar-2011 \\
\hline Complete List of Authors: & $\begin{array}{l}\text { Kautonen, Teemu; University of Turku, TSE Entre } \\
\text { van Gelderen, Marco; Massey University } \\
\text { Tornikoski, Erno; ESC Saint-Etienne }\end{array}$ \\
\hline JEL Code: & $\begin{array}{l}\text { J23 - Employment Determination; Job Creation; Labor Demand; } \\
\text { Self-Employment < J2 - Time Allocation, Work Behavior, and } \\
\text { Employment Determination/Creation < J - Labor and Demographic } \\
\text { Economics, J24 - Human Capital|Skills/Occupational Choice|Labor } \\
\text { Productivity < J2 - Time Allocation, Work Behavior, and } \\
\text { Employment Determination/Creation < J - Labor and Demographic } \\
\text { Economics, M13 - Entrepreneurship < M1 - Business Administration } \\
<\text { M - Business Administration and Business Econ; Marketing; } \\
\text { Accounting }\end{array}$ \\
\hline Keywords: & $\begin{array}{l}\text { occupational choice, self-employment, entrepreneurship, intention, } \\
\text { Theory of Planned Behaviour }\end{array}$ \\
\hline & \\
\hline
\end{tabular}




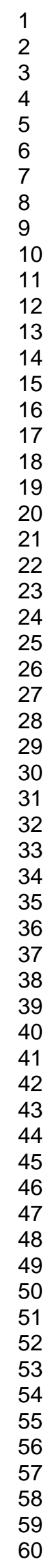

SCHOLARONE ${ }^{m}$
Manuscripts

25

26

27
28

29

30

32

33

34

35

36

37

38

40

41

42

44

45

46

47

48

49

51

52

54

55

57

58

59

60 


\section{Predicting entrepreneurial behaviour: a test of the theory of planned behaviour}

\section{Introduction}

The extant literature often models participation in entrepreneurship as a utilitymaximizing occupational choice between self-employment and paid employment (e.g., Blanchflower et al., 2001; Moore and Mueller, 2002; Rojas and Siga, 2009; Uusitalo, 2001; for an overview, see chapter 2 in Parker, 2009). A recent article in this journal extends this model by analysing the occupational choice of selfemployment as an ordinal variable comprising several stages, thus accounting for the process nature of new venture creation (van der Zwan et al., 2010). The econometric models in van der Zwan et al. (2010) employ a range of demographic determinants and individual perceptions related to the economic environment. The present article extends this research by introducing psychological constructs to explain an individual's progress across different entrepreneurial engagement levels (entrepreneurial behaviour) by applying Ajzen's (1991) Theory of Planned Behaviour (TPB). Originating from social psychology, the TPB works on the assumption that intention is a significant predictor of behaviour, while intention itself is a function of behavioural beliefs that link the given behaviour to certain outcomes. In the entrepreneurial context, the TPB thus contributes to our understanding of the emergence of entrepreneurial behaviour prior to the onset of any observable action, which has notable implications for policy, for example if the objective is to promote enterprising activity by fostering a culture conducive to entrepreneurship (Kautonen et al., 2009; Liñán and Chen, 2009). 
A great deal of cross-disciplinary research has been devoted to testing, advancing and criticizing the TPB (for overviews in social psychology, see the metaanalyses by Armitage and Conner, 2001 and Sheeran, 2002; for applications of the TPB to analyse diverse economic behaviours, see for example d'Astous et al., 2005; East, 1993; Lynne et al., 1995). In the entrepreneurial context, many studies have applied the TPB to predict the intention to start a business, albeit often using convenience samples of university students (e.g., Autio et al., 2001; Kolvereid, 1996; Krueger et al., 2000; van Gelderen et al., 2008). This body of literature also argues that the TPB provides more predictive power in this context than personality traits or demographic characteristics (Autio et al., 2001; Krueger et al., 2000), which are common in the occupational choice literature pertaining to entrepreneurship (see Parker, 2009 for an overview). As Krueger and his colleagues (2000: 413) put it, scholars best predict any planned behaviour, such as entrepreneurship, 'by observing intentions toward that behaviour-not by attitudes, beliefs, personality, or mere demographics'. The intention construct and its antecedents are 'closer to the action' than more distal constructs such as traits and demographics, which may predict broad classes of behaviour well, but not specific actions (Epstein and O'Brien, 1985; Rauch and Frese, 2007), and whose effects the more immediate, proximal TPB constructs mediate (Ajzen, 1991; 2011). In other words, distal constructs such as traits and demographics are antecedents of the more proximal constructs in the TPB model, where intention is the immediate predictor of behaviour.

In spite of the established stream of scholarship explaining the formation of entrepreneurial intentions, the authors of the present article are not aware of a single empirical study that would use longitudinal data to examine whether the intention to start a business measured at one point of time translates into subsequent 
entrepreneurial behaviour. In fact, many scholars identify the lack of such studies as a major shortcoming of the extant literature on business start-up intentions (e.g., Krueger et al., 2000; Souitaris et al., 2007). Moreover, even though the results of previous research generally support the efficacy of the TPB as a predictor of entrepreneurial intentions, the predominant use of student samples limits the generalizability of the results. Therefore, entrepreneurship scholars call for tests of intentions models on samples of subjects in different stages of life (Peterman and Kennedy, 2003).

The principal contribution of this article is to present a full test of the TPB in the context of business start-up intentions and subsequent behaviour by examining two-wave survey data on the working-age population of Western Finland with a three-year gap between the data collection for the intention (2006) and the behaviour items (2009). By testing the full TPB model according to Ajzen's (2011) current specification, this study provides the foundation for further research that aims to incorporate new developments in the model, and thereby increase our understanding of the emergence of entrepreneurial behaviour. The study further contributes to the generalization of the results obtained in previous studies of entrepreneurial intentions by employing data that comprises working-age individuals (18-64 years) instead of a convenience sample of students. The contribution of the study is not limited to the literature on entrepreneurship as an occupational choice, however, but it also contributes to economic literature more generally by providing an example of the efficacy of the TPB as a predictor of an economic behaviour that is rare, obscure and often involves unpredictable time lags (Krueger et al., 2000).

The remainder of this article is arranged as follows. Section II introduces the TPB model and the research hypotheses. Section III presents the empirical data, 


\title{
II. Theoretical framework and research hypotheses
}

\begin{abstract}
Ajzen (2011) provides a generic definition of intention as 'a person's readiness to perform a given behavior'. In the entrepreneurial context, Thompson $(2009$, p. 676) defines intention as 'a self-acknowledged conviction by a person that they intend to set up a new business venture and consciously plan to do so at some point in the future'. In the TPB framework, intention is a function of three antecedents: a favourable or unfavourable evaluation of the behaviour (attitude), perceived social pressure to perform or not perform the behaviour (subjective norm), and the perceived ease or difficulty of performing the behaviour (Perceived Behavioural Control, PBC) (Ajzen, 1991). Applied to the entrepreneurial context, the more positive an individual's evaluations of engaging in entrepreneurial behaviour are, the more supportive of entrepreneurial behaviour the individual perceives their significant others to be, and the more capable they feel of performing entrepreneurial activities, the stronger should be their intention, ceteris paribus, to engage in entrepreneurial behaviour. Prior applications of the TPB in the entrepreneurship literature suggest that attitude, subjective norms, and PBC typically explain 30-45\% of the variance in intentions (Autio et al., 2001; Kolvereid, 1996; Krueger et al., 2000; Liñán and Chen, 2009; Van Gelderen et al., 2008). Therefore:
\end{abstract}

H1a. An entrepreneurially favourable attitude is positively related to entrepreneurial intention. 
H1b. An entrepreneurially favourable subjective norm is positively related to entrepreneurial intention.

H1c. PBC is positively related to entrepreneurial intention.

The TPB further posits that intention provides a link between the three antecedents and subsequent behaviour. Reviewing different meta-analyses covering diverse behavioural domains, Sheeran (2002) reports a mean correlation of 0.53 between intention and behaviour, while Armitage and Conner (2001) find a mean correlation of 0.47 in their meta-analysis focusing on the efficacy of the TPB. Although there are no full tests of the TPB in the context of business start-ups, studies exist in the enterprise literature that shed indirect evidence on the intentionbehaviour relationship. For example, Henley (2007) investigated whether statements of entrepreneurial aspirations precede transitions into self-employment one year later. He studied employees with no current business ventures, and asked them whether they would like to start a (new) business in the next 12 months. His data show that only $8 \%$ of individuals with initial aspirations had become self-employed one year later. Using cross-sectional data from a variety of European countries and the United States, Grilo and Irigoyen (2006) found that preference levels pertaining to self-employment are higher than the actual realization levels. Blanchflower and Oswald (1998) and Blanchflower et al. (2001) report similar cross-sectional results. While these results hint at a possible gap in the intention-behaviour relationship, the cited studies do not demonstrate whether the underlying cause is people not acting on their preferences, or these actions not resulting in operational businesses. Based on the theoretical specification of the TPB and the available indirect empirical evidence, this study proposes: 
$\mathrm{H} 2 \mathrm{a}$. Entrepreneurial intention is positively related to subsequent entrepreneurial behaviour.

Further, Ajzen (1991) argues that intention is a sufficient predictor of behaviour in situations where the individual has a very high degree of volitional control over the behaviour. However, in situations where there are problems with volitional control, $\mathrm{PBC}$ should be additionally and independently predictive of behaviour. The rationale is that individuals will exert additional effort given increased feelings of control and that action not only depends on intentions but also on non-motivational factors such as the availability of opportunities and resources. Jointly, Ajzen (1991) argues, these factors constitute people's actual control of the behaviour in question and to the extent that perceived control is realistic, it can serve as a substitute for actual control. Since entrepreneurial behaviour is not totally under the individual's volitional control - for example, dealing with regulations, obtaining financing and acquiring customers introduce contingencies to the process of new venture creation that are beyond the aspiring entrepreneur's complete control - PBC is likely to contribute to the prediction of behaviour over and above its mediated influence via intention. Hence:

$\mathrm{H} 2 \mathrm{~b} . \mathrm{PBC}$ is positively related to subsequent entrepreneurial behaviour, over and above its mediated effect via intention.

Fig. 1 summarizes the TPB model and the hypothesized relationships. 


\title{
INSERT FIG. 1 ABOUT HERE
}

\author{
III. Data \\ Data collection
}

The research team collected the survey data in the provinces of Central Ostrobothnia, Ostrobothnia and South Ostrobothnia in Western Finland in November 2006 (first wave) and November 2009 (second wave) as part of a research project on Ostrobothnian entrepreneurship. Finland as a whole has a moderate level of entrepreneurial activity compared to many other countries in the Global Entrepreneurship Monitor surveys (e.g., Pukkinen et al., 2007; Stenholm et al., 2009). Of course, there are regional variations in the rates of enterprising activity in Finland and the three provinces included in this study represent this diversity fairly well. For example, the province of Ostrobothnia has a relatively low level of entrepreneurial activity, while South Ostrobothnia has one of the highest entrepreneurial activity levels in the country (Hyrsky and Lipponen, 2004). Thus, the empirical results should not be biased because of excessive homogeneity of the regional sample in terms of the level of entrepreneurial activity.

In the first wave of data collection the researchers mailed 5600 questionnaires to a random sample of individuals aged 15-74, obtained from the Finnish Population Register Centre. Hence, this study overcomes the common limitation in entrepreneurial intentions research of using convenience samples consisting of (university) students. The survey was anonymous, but the respondents could indicate their willingness to participate in a follow-up study and provide their contact details. 
The survey resulted in a total of 1301 responses (response rate: $23.2 \%$ ). Following the archival analysis approach to examining non-response bias (Rogelberg and Stanton, 2007), the researchers compared the sample with the original list received from the Population Register Centre containing the names, addresses, sex, and year of birth of all 5600 people to whom the questionnaire was sent. This list of 5600 individuals is representative of the working-age population in the three Western Finnish provinces. The comparison shows that the average age of the respondents in the sample is slightly higher (45.1 years) than in the original list (43.4 years).

Moreover, women have a higher comparative participation rate than men, since $58 \%$ of the respondents in the sample are female compared with $49 \%$ in the original list. Eight percent of the respondents were self-employed already, and were thus excluded from further consideration in this study. The 2006 data collection covers all variables in the research model, excluding the primary dependent variable, entrepreneurial behaviour.

The second-wave survey collected data on entrepreneurial behaviour, and included those first-wave respondents who were not self-employed in 2006 and who had given their permission and contact details for a follow-up study (29\% of those not self-employed in 2006). Consequently, the research team sent out 354 questionnaires by post and via e-mail (depending on the respondent's preference), resulting in 132 responses (response rate: $37.3 \%$ ). A meaningful analysis of the intention-behaviour relationship requires a sufficient number of responses from individuals with high intentions ('intenders'). Whereas for the prediction of intentions the entire population is of interest, this is far less the case for the intentionbehaviour link, which is concerned with whether intenders subsequently take action, not with whether non-intenders do not take action. Sheeran (2002) in fact shows that 
non-intenders showing behaviour are rare. In order to ensure a sufficient number of intenders in the longitudinal sample, the research procedure included 29 phone calls to individuals with high intentions in 2006 (6\% of the sample had a score of 5 or higher on our 7-point intention scale, where a high score stands for high intention), with the purpose of motivating them to return the questionnaire, when they had not done so by the initial deadline. The downside of the over-sampling strategy is that it may increase the risk of type II error. However, our research design reduces type II error by allowing a three-year period to pass between the measurement of intention and actual behaviour (Sutton, 1998), which limits the risk of people being classified as not engaging in entrepreneurial behaviour even if they do eventually start a business after three years.

The following analysis focuses on working-age individuals (18-64 years in 2006; this is also the age bracket employed in the influential Global Entrepreneurship Monitor, see Kelley et al., 2010) who were not self-employed in 2006, resulting in a final two-wave sample of 117 individuals.

\section{Covariates}

The primary dependent variable in this study, entrepreneurial behaviour, captures whether and how the respondent had engaged in entrepreneurial behaviour by the time of the second survey wave in November 2009. The operationalization of this variable relies on the concept of the entrepreneurial ladder (van der Zwan et al., 2010). Instead of treating the decision to become an entrepreneur as a binary occupational choice between paid employment and self-employment, the concept of the entrepreneurial ladder understands it as a process consisting of a series of naturally ordered engagement levels where each level represents an increasing level 
of involvement in the entrepreneurial process. Operationalizing entrepreneurial behaviour in terms of different engagement levels is in line with the TPB (Ajzen, 1985), where behaviour refers to making an effort to start a business rather than achieving the outcome of having started a business. Thus, the operationalization based on the entrepreneurial ladder distinguishes between different degrees of effort the individual has invested in the process of starting a business. The respective question in the survey instrument for forming this variable is: 'In the last three years (that is, from November 2006 on), have you started a business or thought about starting a business alone or together with others?' (translated from Finnish). The respondent could choose between four options: 1) have not thought about starting a business; 2) thought about it but have not taken action; 3) have not started a business but have commenced preparations and intend to start up in the near future; and 4) have started a business. The variable employed in the econometric analysis is therefore an ordinal variable comprising four engagement levels.

According to Thompson (2009), having entrepreneurial intention is not a simple yes or no question but a matter of extent ranging from very low to very high. Hence, this research uses an ordinal scale based on the question 'How likely is it that you will start your own business?' to form the measure of intention. On this scale, a score of 1 indicates very low intentions and a score of 7 very high intentions to start a business. This question yields a so-called behavioural expectancy measure of intention (van Gelderen et al., 2008). Previous literature argues and finds that behavioural expectancies provide better predictions of behaviour than other measures of intention (Sheppard et al., 1988; Warshaw and Davis, 1985). The rationale is that behavioural expectancies include considerations regarding the possible choice of other competing behaviours (Armitage and Conner, 2001; Silvia, 2001), whereas 
non-committal measures, such as preferences which entrepreneurship studies also commonly use (e.g., Kolvereid, 1996), take no account of facilitating or inhibiting factors. Although the literature often uses psychometric scales to measure entrepreneurial intentions (for recent scale development efforts, see e.g., Liñan and Chen, 2009; Thompson, 2009), the use of single-item measures is not uncommon (Autio et al., 2001; Krueger et al., 2000; Peterman and Kennedy, 2003). In particular, researchers commonly apply single-item measures when measuring expectancies and such measures suffice when constructs are sufficiently narrow and unambiguous to the respondent (Wanous et al., 1997). The intention measure in the present study fulfils these criteria and is similar to formulations in prior research on entrepreneurial intentions (Autio et al., 2001; Kolvereid, 1996; Krueger et al., 2000).

The psychometric scale used to measure $P B C$ is based on the one developed by Kolvereid (1996) (see Appendix 1 for the wordings of all psychometric scale items). Following Ajzen's (2002) arguments against the use of items referring to outcomes (such as expected chances of success), we excluded three items (items 3, 5, and 6 in Kolvereid 1996, p. 52) as they do not relate to the actual behaviour in question. Thus, the initial index for PBC in this study comprised the three items displayed in Appendix 1. Ajzen's (2002) conceives of PBC as an overarching construct that entails both self-efficacy and control. However, the item referring to issues outside one's control that prevent one from starting a business (item 4 in Kolvereid 1996, p. 52) lowered the scale's reliability considerably. Therefore, the authors decided to apply a two-item index of PBC where a high score signifies that the individual finds starting a business relatively easy (Cronbach's alpha: 0.82).

Following Kolvereid (1996), the independent variable, subjective norm, is the product of two sets of psychometric measures, each using a seven-point Likert scale. 
The first set contains three items measuring the individual's beliefs concerning whether their family, friends, and colleagues or other important people think that the individual should or should not start up in business. The second set of measures captures the degree to which those people's opinions impact on the individual's decision as to whether or not to start a business. The researchers first multiplied the corresponding pairs of the belief and motivation-to-comply items and subsequently added the three products up to form a final index (Cronbach's alpha: 0.80). A high score indicates that the individual's significant others are supportive of them starting a business, and that those people's opinions matter to the individual.

A total of 15 items adapted from Kolvereid (1996) measure attitude in this survey. Following Kolvereid (1996), the researchers first reduced the 15 items to five indices by averaging the respective item scores. Three of these indices measure attitudes favourable to enterprising behaviour: authority and autonomy (four items, Cronbach's alpha: 0.79), self-realization (three items, Cronbach's alpha: 0.69) and economic opportunity (two items, Cronbach's alpha: 0.63 ). The remaining two indices represent attitudes that favour paid employment: security (two items, Cronbach's alpha: 0.67) and avoid responsibility (three items, Cronbach's alpha: 0.70). Next, the researchers reduced the five indices down to two, representing attitudes favouring business ownership or paid employment, by adding up the respective index scores. Hence, the index measuring attitudes favourable to business ownership is the linear sum of authority and autonomy, self-realization and economic opportunity, while the index capturing attitudes favourable to paid employment is the sum of security and avoid responsibility. Finally, the difference between these two measures forms an index of occupational choice attitude so that a high positive score indicates an attitude towards work that is conducive to 
entrepreneurship, while a low positive or a negative score refers to attitudes that favour paid employment.

In order to monitor for effects that might otherwise influence intention or behaviour, the model specification includes the respondent's sex (dummy with female coded as 1) and age in a quadratic specification as control variables. The researchers chose these particular variables because prior econometric evidence shows that women are generally less likely to engage in entrepreneurial behaviour than men (e.g., Kelley et al., 2010) and that age is one of the most important determinants of entrepreneurship (Parker, 2009).

\section{Sample characteristics}

Table 1 presents the descriptive statistics including a comparison of the first and second survey waves. In order to facilitate comparability, the first-wave statistics include only the 18-64 year old respondents and exclude those who were selfemployed in 2006. The test statistics in the final column show that individuals who participated in both survey waves have significantly higher scores for entrepreneurial intentions and their antecedents (attitude, subjective norm, and PBC) than the respondents who only participated in the first wave. This is most likely due to the over-sampling of individuals with high intentions. Further, in order to detect potential sources of multicollinearity, the authors examined the inter-correlations between the exogenous variables. The analysis revealed significant inter-correlations between attitude, subjective norms and PBC, with the respective Pearson productmoment correlation coefficients ranging from 0.22 to 0.50 , thus signalling a potential risk of multicollinearity. However, since all Variation Inflation Factor (VIF) values for these variables are clearly below the conventional threshold of 10 , the highest 
value being 1.5 , multicollinearity does not appear to be a serious problem in this analysis.

\section{INSERT TABLE 1 ABOUT HERE}

\section{Analysis strategy}

Since the model includes factors and mediating effects, this study opts for Structural Equation Modelling (SEM) as the means to test its hypotheses. Given the sample size of only 117 observations, the analysis applies the total aggregation approach (Bagozzi and Heatherton, 1994) to the factors in order to optimize sample size relative to the parameter estimates, while accounting for measurement errors. In other words, the model treats the indices computed for the psychometric constructs (attitude, subjective norms, and PBC) as observed variables, which are assigned as single-item indicators to the corresponding latent variables. Correction for measurement errors involves fixing the latent-to-manifest parameters to 1, and assigning a value of 1 minus the reliability (Cronbach's alpha) multiplied by the variable's variance, to each residual. This procedure is common in SEM (e.g., Carlson and Kacmar, 2000; Williams and Hazer, 1986), and the study by Netemeyer et al. (1990) suggests that this procedure generates results that are virtually identical to a full latent variable model.

The analysis uses the MPlus Version 6 software package, which can accommodate probit regressions into structural equation models with the WLSMV estimator (Muthén and Muthén, 1998-2010; Xie, 1999), thus enabling the modelling of ordinal response variables (intention and behaviour) in the SEM framework. The WLSMV estimator generates weighted-least-square parameter estimates employing a 
diagonal weight matrix with robust standard errors and mean and variance adjusted chi-square test statistics (Muthén and Muthén, 1998-2010), which are suitable for models with categorical dependent variables (Brown, 2006; Muthén, 1983).

\section{Results}

Table 2 displays the results of the structural model estimation. The estimated model shows good fit with the data: the chi-square test of model fit is non-significant; the comparative fit index (CFI) exceeds the recommend minimum value of 0.95; the root-mean-square error (RMSEA) score is below the recommended maximum value of 0.06; and the weighted root-mean-square residual (WRMR) is less than the recommended maximum value of 0.90 for models with categorical dependent variables (Hu and Bentler, 1999; Yu and Muthén, 2002).

\section{INSERT TABLE 2 ABOUT HERE}

The path coefficients show that attitude, subjective norms, and PBC exert a significant impact on intention at the $1 \%$ level. Hence, the results support the hypothesized effects of the three antecedents on intentions (H1a, H1b, and H1c). The model estimations further show that intention and PBC are significant predictors of entrepreneurial behaviour, also at the $1 \%$ significance level. Moreover, the results support the proposition in the TPB that intentions mediate the effects of the three antecedents: the indirect effects from attitude, subjective norms, and PBC on behaviour via intention (not shown in Table 2) are all significant at the 5\% level. The significant effect of intention on behaviour supports H2a. PBC, having both a 
significant direct and a significant indirect effect on behaviour, provides support to $\mathrm{H} 2 \mathrm{~b}$.

Overall, the model accounts for $41 \%$ and $39 \%$ of the variance in the continuous latent variable underlying the ordered categorical measures of intention and behaviour, respectively. Statistical research shows that this particular pseudo Rsquared (McKelvey and Zavoina, 1975) is very similar to the R-squared in Ordinary Least Squares (OLS) regression (Hox, 2009; Long, 1997). Thus, this estimate is reasonably comparable to the OLS R-squared reported in prior tests of the TPB that use continuous psychometric measures of intention and behaviour (see Section II).

\section{Conclusion}

This study investigates the efficacy of the TPB in predicting entrepreneurial behaviour in a sample of 117 working-age individuals from Western Finland. While there is an abundance of studies examining the formation of entrepreneurial intentions - often with demographically limited samples, such as university students - there is at the same time a lack of evidence pertaining to the link between entrepreneurial intention and subsequent behaviour.

The empirical analysis supports the TPB and prior research in the field of entrepreneurship and other research domains in showing that attitude, subjective norms, and PBC are significant predictors of entrepreneurial intentions. The particular novelty of the paper is in including a test of the 'right-hand side' of the TPB model - the predicted causal effects from intention and PBC on behaviour which had not been tested previously in the context of business start-ups. The results show that intention and PBC are significant predictors of whether an individual 
subsequently engages in entrepreneurial behaviour. In terms of explained variance, the results of this research suggest that the predictive relevance of the TPB in the business start-up context is roughly in line with results from other domains that involve medium-term goals that require considerable effort to attain, such as healthrelated goals (Armitage and Conner, 2001; Sheeran, 2002). In summary, the results support the predictive validity of the TPB in the context of business start-up behaviour.

Two limitations affect the generalizability of the study's results. The first limitation is the small number of respondents who participated in both waves of the survey $(N=117)$, while the second limitation refers to the geographic scope of the sample being limited to three Finnish provinces. Only a sufficiently large international sample would enable us to draw solid conclusions regarding the causality in the intention-behaviour link in the TPB model. Hence, future studies should seek to obtain larger, preferably cross-cultural samples to validate the preliminary findings presented in this article. Moreover, future research should distinguish between different types of entrepreneurship, such as full-time and parttime entrepreneurship, sole proprietorships and businesses with employees, lifestyle businesses and those with growth aspirations, opportunity and necessity-driven entrepreneurship, or for-profit and social enterprises. These distinctions are of considerable relevance to policy, for example, in terms of assessing the social and economic potential of latent entrepreneurship in different segments of the population, and in targeting and designing enterprise support initiatives.

In spite of the limitations, this article demonstrates the potential of the TPB in studying the emergence of complex economic behaviour such as entrepreneurship prior to the onset of any observable action. This understanding can have notable 
policy implications. For example, policy-makers wishing to encourage more enterprising activity may target the attitudes and norms pertaining to entrepreneurship in initiatives aimed at increasing people's motivation towards entrepreneurship as an occupational choice. Similarly, policy-makers may design entrepreneurship education provision to increase the $\mathrm{PBC}$ related to entrepreneurship in the target segment.

\section{Acknowledgements}

This research received support from the Academy of Finland.

\section{References}

Ajzen, I. (1985) From intentions to actions: a theory of planned behaviour, in Action Control: From Cognition to Behavior, (Eds) J. Kuhl and J. Beckmann, Springer, Heidelberg, pp. 11-39.

Ajzen, I. (1991) The theory of planned behavior, Organizational Behavior and Human Decision Processes, 50, 179-211.

Ajzen, I. (2002) Perceived behavioural control, self-efficacy, locus of control, and the theory of planned behaviour, Journal of Applied Social Psychology, 32, 66583.

Ajzen, I., 2011. Theory of planned behavior. Retrieved from: http://www.people.umass.edu/aizen/tpb (accessed 24 February 2011).

Armitage, C. J. and Conner, M. (2001) Efficacy of the theory of planned behaviour: a meta-analytic review, British Journal of Social Psychology, 40, 471-99. 
Autio, E., Keeley, R. H., Klofstein, M., Parker G. G. C. and Hay, M. (2001) Entrepreneurial intent among students in Scandinavia and in the USA, Enterprise and Innovation Management Studies, 2, 145-60.

Bagozzi, R. P. and Heatherton, T. F. (1994) A general approach to representing multifaceted personality constructs: application to state self-esteem, Structural Equation Modeling: A Multidisciplinary Journal, 1, 35-67.

Blanchflower, D. G. and Oswald, A. (1998) What makes an entrepreneur?, Journal of Labor Economics, 16, 16-60.

Blanchflower, D. G., Oswald, A. and Stutzer, A. (2001) Latent entrepreneurship across nations, European Economic Review, 45, 680-91.

Brown, T. A. (2006) Confirmatory Factor Analysis for Applied Research, Guildford Press, New York.

Carlson, D. S. and Kacmar, K. M. (2000) Work-family conflict in the organization: do life role values make a difference?, Journal of Management, 26, 1031-54.

d'Astous, A., Colbert, F. and Montpetit, D. (2005) Music piracy on the web - how effective are anti-piracy arguments? Evidence from the theory of planned behaviour, Journal of Consumer Policy, 28, 289-310.

East, R. (1993) Investment decisions and the theory of planned behavior, Journal of Economic Psychology, 14, 337-375.

Epstein, S., and O'Brian, E. J. (1985) The person-situation debate in historical and current perspective, Psychological Bulletin, 98, 513-537.

Grilo, I. and Irigoyen, J.M. (2006) Entrepreneurship in the EU: to wish and not to be, Small Business Economics, 26, 305-18. 
Henley, A. (2007) Entrepreneurial aspiration and transition into self-employment: evidence from British longitudinal data, Entrepreneurship \& Regional Development, 19, 253-80.

Hox, J. J. (2009) Multilevel Analysis: Techniques and Applications, Routledge, New York.

Hu, L. and Bentler, P.M. (1999) Cutoff criteria for fit indexes in covariance structure analysis: conventional criteria versus new alternatives, Structural Equation Modeling: A Multidisciplinary Journal, 6, 1-55.

Hyrsky, K. and Lipponen, H. (2004) Yrittäjyyskatsaus 2004, Publications of the Ministry of Trade and Industry, 18/204, Edita, Helsinki.

Kautonen, T., Tornikoski, E. T. and Kibler, E. (2009) Entrepreneurial intentions in the third age: the impact of perceived age norms, Small Business Economics, DOI: 10.1007/s11187-009-9238-y.

Kelley, D., Bosma, N., Amorós, J. E. (2010) Global Entrepreneurship Monitor 2010 Global Report, Babson College, Wellesley.

Kolvereid, L. (1996) Prediction of employment status choice intentions, Entrepreneurship Theory and Practice, 21, 47-57.

Krueger, N. F., Reilly M. D. and Carsrud, A. L. (2000) Competing models of entrepreneurial intentions, Journal of Business Venturing, 15, 411-32.

Liñán, F. and Chen, Y.-W. (2009) Development and cross-cultural application of a specific instrument to measure entrepreneurial intentions, Entrepreneurship Theory and Practice, 33, 593-617.

Long, J. S. (1997) Regression Models for Categorical and Limited Dependent Variables, Sage, Thousand Oaks. 
Lynne, G. D., Casey, C. F., Hodges, A. and Rahmani, M. (1995) Conservation technology adoption decisions and the theory of planned behavior, Journal of Economic Psychology, 16, 581-598.

McKelvey, R. D. And Zavoina, W. (1975) A statistical model for the analysis of ordinal level dependent variables, Journal of Mathematical Sociology, 4, 103-20.

Moore, C. S. and Mueller, R. E. (2002) The transition from paid to self-employment in Canada: the importance of push factors, Applied Economics, 34, 791-801.

Muthén, B. O. (1983) Latent variable structural equation modeling with categorical data, Journal of Econometrics, 22, 43-65.

Muthén, L. K., Muthén, B. O. (1998-2010). Mplus User's Guide, $6^{\text {th }}$ edn, Muthén \& Muthén, Los Angeles.

Netemeyer, R. G., Johnston, M. W. and Burton, S. (1990) Analysis of role conflict and role ambiguity in a structural equations framework, Journal of Applied Psychology, 75, 148-57.

Parker, S. C. (2009) The Economics of Entrepreneurship, Cambridge University Press, Cambridge.

Peterman, N. E. and Kennedy, J. (2003) Enterprise education: influencing students' perceptions of entrepreneurship, Entrepreneurship Theory and Practice, 28, 12944.

Pukkinen, T., Stenholm, P., Heinonen, J., Kovalainen, A. and Autio, E. (2007) Global Entrepreneurship Monitor: 2006 Executive Report Finland. Turku School of Economics, Series B Research Reports, B1 / 2007.

Rauch, A., and Frese, M. (2007) Born to be an entrepreneur? Revisiting the personality approach to entrepreneurship, in The Psychology of Entrepreneurship, 
(Eds) R.A. Baron, M. Frese, and J.R. Baum, Lawrence Erlbaum, Mahwah NJ, pp. $41-65$

Rogelberg, S. G., Stanton, J. M. (2007) Understanding and dealing with organizational survey nonresponse, Organizational Research Methods, 10, 195209.

Rojas, G. V. M. and Siga, L. (2009) On the nature of micro-entrepreneurship: evidence from Argentina, Applied Economics, 41, 2667-80.

Sheeran P. (2002) Intention-behaviour relations: a conceptual and empirical overview, European Review of Social Psychology, 12, 1-36.

Sheppard, B. H., Hartwick, J. and Warshaw, P. R. (1988) The theory of reasoned action: A meta-analysis of past research with recommendations for modifications and future research, Journal of Consumer Research, 15, 325-43.

Silvia, P. J. (2001) Expressed and measured vocational interests: distinctions and definitions, Journal of Vocational Behaviour, 59, 382-93.

Souitaris, V., Zerbinati, S. and Al-Laham, A. (2007) Do entrepreneurship programmes raise entrepreneurial intention of science and engineering students? The effect of learning, inspiration and resources, Journal of Business Venturing, 22, 566-91.

Stenholm, P., Pukkinen, T., Heinonen, J. and Kovalainen, A. (2009) Global Entrepreneurship Monitor: Finnish 2008 Report, Turku School of Economics, Series A Research Reports, A1 / 2009.

Sutton, S. (1998) Predicting and explaining intentions and behaviour: how well are we doing?, Journal of Applied Social Psychology, 28, 1317-38. 
Thompson, E. R. (2009) Individual entrepreneurial intent: construct clarification and development of an internationally reliable metric, Entrepreneurship Theory and Practice, 33, 669-94.

Uusitalo, R. (2001) Homo entreprenaurus?, Applied Economics, 33, 1631-1638.

Van der Zwan, P., Thurik, R. and Grilo, I. (2010) The entrepreneurial ladder and its determinants, Applied Economics, 42, 2183-91.

Van Gelderen, M., Brand, M., Van Praag, M., Bodewes, W., Poutsma, E. and Van Gils, A. (2008) Explaining entrepreneurial intentions by means of the theory of planned behaviour, Career Development International, 13, 538-59.

Wanous, J.P., Reichers, A.E., and Hudy, M.J. (1997) Overall job satisfaction: How good are single-item measures?, Journal of Applied Psychology, 82, 247-252.

Warshaw, P. R. and Davis, F. D. (1985) Disentangling behavioural intention and behavioural expectation, Journal of Experimental Social Psychology, 21, 213-28.

Williams, L. J. and Hazer, J. T. (1986) Antecedents and consequences of satisfaction and commitment in turnover models: a reanalysis using latent variable structural equation methods, Journal of Applied Psychology, 71, 219-31.

Xie, Y. (1989) Structural equation models for ordinal variables: an analysis of occupational destination, Sociological Methods \& Research, 17, 325-52.

Yu, C. and Muthén, B. O. (2002) Evaluation of the model fit indices for latent variable models with categorical and continuous outcomes. Paper presented at the annual meeting of the American Educational Research Association, New Orleans. 


\section{Appendix 1. Psychometric scale items}

Subjective norm $^{\mathrm{a}}$

I believe that my closest family members think that I should not/should pursue starting my own business and becoming an entrepreneur * motivation to comply

I believe that my closest friends think that I should not/should pursue starting my own business and becoming an entrepreneur * motivation to comply

I believe that my colleagues and people important to me think that I should not/should pursue starting my own business and becoming an entrepreneur * motivation to comply

Perceived behavioural control (PBC)

For me starting my own firm and becoming an entrepreneur would be (very difficult very easy)

If I wanted to, I could easily pursue a career as an entrepreneur

There are (very few - very many) such issues that I cannot influence myself but that prevent me from starting a business

Authority and autonomy ${ }^{\mathrm{b}}$

I look for independence

I want decision-making power

I look for a position of authority

I would like to be my own boss

Self-realization ${ }^{\mathrm{b}}$

I would like to make use of my creativity

I would like to carry out my dreams

I would like to create something new 
Economic opportunity ${ }^{\mathrm{b}}$

I would like a large share of my salary to be based on results

I would like to be paid based on my achievements

Avoidance of responsibility

I do not want to take on many tasks with responsibility

I want to avoid excessive commitment to my work

I want to avoid responsibility

Security $^{\mathrm{b}}$

The stability of employment is very important to me

The continuity of employment is very important to me

\footnotetext{
${ }^{a}$ The subjective norm scores were calculated by multiplying the item score for the belief statement (shown in the table) with the item score for the motivation to comply, which was measured by asking 'How much do you care what the following people think if you strive to start your own business?' and providing a list of groups of people to match the belief statements.

${ }^{\mathrm{b}}$ These items were measured as responses to the general question 'To what extent do you agree or disagree with the importance of the following items in terms of your working career?' ( 1 for definitely disagree; 7 for definitely agree).
} 
Fig. 1. Theory of Planned Behaviour (TPB) and research hypotheses

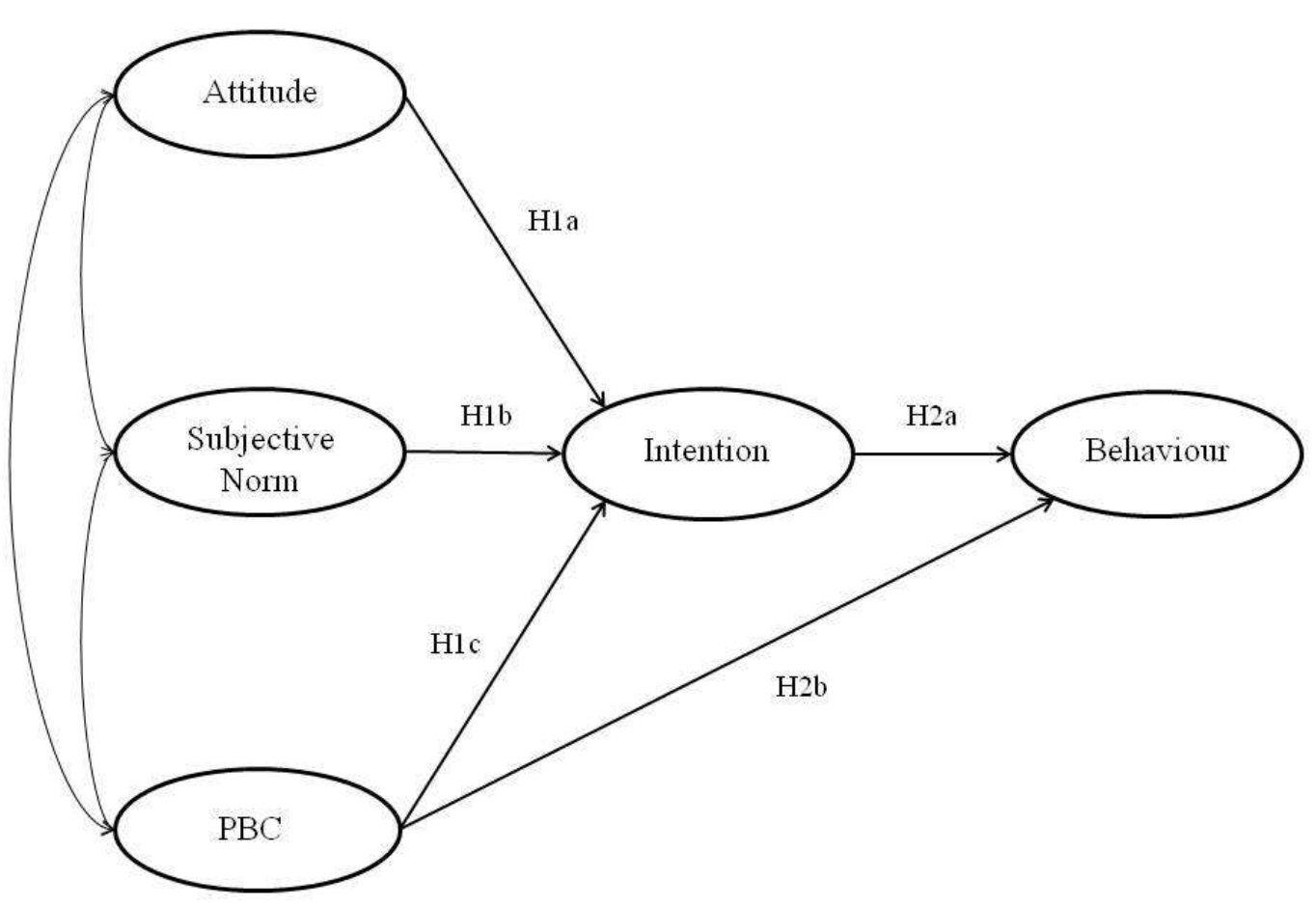


Table 1. Descriptive statistics

\begin{tabular}{|c|c|c|c|c|c|c|c|c|c|}
\hline & \multicolumn{2}{|c|}{ Range } & \multicolumn{2}{|c|}{$\begin{array}{l}\text { (1) First wave } \\
\text { (all, N=992) }\end{array}$} & \multicolumn{2}{|c|}{$\begin{array}{l}\text { (2) First wave } \\
\text { (not in second wave, } \\
\mathrm{N}=875 \text { ) }\end{array}$} & \multicolumn{2}{|c|}{$\begin{array}{l}\text { (3) Second wave } \\
(\mathrm{N}=117)\end{array}$} & \multirow{2}{*}{$\begin{array}{l}\begin{array}{l}\text { Difference } \\
(2) \text { and (3) }\end{array} \\
\begin{array}{l}t \text {-statistic / } \\
\text { chi-square }\end{array}\end{array}$} \\
\hline & Min & Max & Mean & SD & Mean & SD & Mean & SD & \\
\hline \multicolumn{10}{|l|}{ Behaviour } \\
\hline (0) Not considered starting a business & & & & & & & $50.8 \%$ & & \\
\hline (1) Thinking about it & & & & & & & $33.3 \%$ & & \\
\hline (2) Taking steps & & & & & & & $6.0 \%$ & & \\
\hline (3) Started in last 3 years & & & & & & & $9.4 \%$ & & \\
\hline Intention & 1 & 7 & 2.52 & 1.79 & 2.45 & 1.77 & 3.04 & 1.88 & $3.362 * *$ \\
\hline Attitude & -11 & 51 & 24.66 & 10.26 & 24.19 & 10.27 & 28.19 & 9.52 & $3.990 * *$ \\
\hline Subjective norm & 3 & 147 & 43.30 & 26.98 & 42.27 & 26.51 & 50.96 & 29.26 & $3.286 * *$ \\
\hline $\mathrm{PBC}$ & 1 & 7 & 3.98 & 1.66 & 3.90 & 1.64 & 4.59 & 1.69 & $4.231 * *$ \\
\hline Age & 18 & 64 & 42.66 & 13.34 & 42.75 & 13.43 & 41.99 & 12.65 & 0.578 \\
\hline Female & 0 & 1 & $61.0 \%$ & & $61.0 \%$ & & $60.7 \%$ & & 0.005 \\
\hline
\end{tabular}


Table 2. Results of the structural equation model estimation

\begin{tabular}{|c|c|c|c|c|c|c|}
\hline \multirow[b]{3}{*}{ Exogenous variables } & \multicolumn{6}{|c|}{ Endogenous variables } \\
\hline & \multicolumn{3}{|c|}{ Intention } & \multicolumn{3}{|c|}{ Behaviour } \\
\hline & StdYX & Coef. & SE & StdYX & Coef. & SE \\
\hline Intention & & & & $0.168 * *$ & 0.167 & 0.059 \\
\hline Attitude & $0.246 * *$ & 0.330 & 0.124 & & & \\
\hline Subjective norm & $0.210^{* *}$ & 0.086 & 0.029 & & & \\
\hline $\mathrm{PBC}$ & $0.249 * *$ & 0.172 & 0.060 & $0.456 * *$ & 0.314 & 0.068 \\
\hline Female & -0.184 & -0.392 & 0.219 & -0.168 & -0.331 & 0.229 \\
\hline Age & -0.245 & -0.020 & 0.050 & -0.469 & -0.024 & 0.053 \\
\hline Age squared & -0.028 & -0.280 & 5.983 & 0.298 & 0.908 & 6.542 \\
\hline R-square & & 0.41 & & & 0.39 & \\
\hline$\chi^{2}$ & \multicolumn{6}{|c|}{$13.66(11 \mathrm{df}), p=0.25$} \\
\hline CFI / RMSEA / WRMR & \multicolumn{6}{|c|}{$0.975 / 0.045 / 0.576$} \\
\hline
\end{tabular}

